\title{
Effet de berge, effet de vase, deux facteurs différents de mobilisation du manganèse : un exemple dans un champ captant de la vallée du Lot (France)
}
B. Garcial
C. Bertin2
J. Ricard ${ }^{3}$
A. Bourg2
P. Lavandier1
L. Labroue ${ }^{1-4}$

Mots clés : Manganèse, rivière, nappe, berge, vase, champ captant.

L'étude de la solubilisation du manganèse dans les eaux des forages du champ captant de Capdenac-Gare (complexe rivière-nappe) met en évidence deux processus différents de réduction du métal :

- l'un, permanent, est lié à la présence de matière organique particulaire enfouie dans les sédiments récents ou déposée sur le fond du Lot, dans les zones de calme ou de retour (effet de vase). L'implantation de forages pompant l'eau au travers de ces zones mène inéluctablement à des concentrations élevées en manganèse et au traitement de l'eau prélevéé ;

- l'autre, saisonnier, est lié à la présence de matière organique dissoute dans l'eau du Lot, essentiellement fournie par le développement algal en été (eutrophisation).

La minéralisation de cette matière organique au niveau de la berge (effet de berge) entraîne la consommation de l'oxygène dissous puis des nitrates accompagnée d'une baisse du potentiel redox. Il s'ensuit une mobilisation du manganèse au niveau des biofilms du milieu poreux, mobilisation favorisée par les températures élevées de l'eau du Lot, en été et en automne.

Lorsque le carbone organique bio-dégradable est épuisé on observe une réoxygénation de la nappe par la surface, accompagnée de la précipitation du manganèse soluble. Il faut donc éviter l'implantation de forages dans la zone réduite et favoriser, lorsque c'est possible, la réoxygénation de la nappe par la surface.

Effects of riverbank and muddy sediment, the two different factors for the mobilisation of manganese : a case study in a well field of the Lot river valley (France)

Keywords : Manganese, river, groundwater, riverbank, mud, well field.

The study of the solubilization of manganese in the groundwater pumped from the well field of Capdenac-Gare (riverbank-aquifer system) highlights two different reducing processes of the metal :

- The first, permanent, is related to the presence of solid organic matter embedded in the recent sediments, or on the river-bottom of the Lot river, in calm sites where fine sediments were deposited (mud effect). When the pumping. wells are located so that the pumped water percolates through these reduced zones, high concentrations of manganese are observed which lead ineluctably to water treatment.

- The other, seasonal, is found in the presence of dissolved organic matter in the Lot river, provided essentially by the development of algae in summer (eutrophication). The mineralization of the organic matter.near the river banks (river bank effect) leads to the consumption of the oxygen and the nitrates accompanied by a decrease of the redox potential. It follows a mobilisation of manganese near the biofilm which envelops the porous media. This mobilisation is favoured by the high temperatures of the Lot river in summer and auturnn.

When all the bio-degradable organic carbon is consumed, we noticed a reoxygenation of the grouridwater by the atmosphere, accompanied by the precipitation of soluble manganese. Therefore, one should avoid the implantation of pumping wells in the reduced zone of the groundwater and favour, whenever possible, the reoxygenation of the groundwater through the soil surface.

1. Laboratoire d'Hydrobiologie, U.R.A.C.N.R.S. 695, Université Paul Sabatiet, 118 route de Narbonne, 31062 Toulouse Cedex, France

2. B.R.G.M. Centre scientifique et technique, Av. de Concyr, Orléans-La Source, B.P. 6009, 45060 Orléans Cedex 1, France.

3. B.R.G.M. Midi-Pyrénées, Av. P.G. Latécoère, B.P. 4404, 31405 Toulouse Cedex, France.

4. Auteur correspondant. 


\section{Introduction}

Jusqự'en 1989, les habitants de la ville de Capdenac-Gare (Aveyron) étaient alimentés en eau potable par une usine de traitement des eaux de la rivière Lot. Actuellement, l'eau provient d'un champ captant de 6 forages, réalisé en 1988-89 par le B.R.G.M. dans un méandre de la rivière, après étude hydrogéologique du site.

Au cours de l'été 1990, la municipalité a été confrontée à des problèmes de dégradation de la qualité de l'eau dans les forages : odeur, goût, présence de manganèse et épisodiquement de fer. De plus, on a noté la formation de dépôts de matière organique dans la bâche de reprise (bassin recueillant les eaux des différents puits avant leur distribution) située près du forage FE9.

Ces phénomènes ont été souvent constatés dans les nappes alluviales en relation avec un cours d'eau de surface (Chauvé et al. 1986, Gounot \& Haroux 1986, Jacobs et al. 1988, Bourg et al. 1989, Gounot \& Di-Ruggiero 1991). Ils compromettent l'utilisation de la nappe comme source d'approvisionnement en eau potable ou oblitèrent l'effet bénéfique de la filtration de la berge pour l'utilisation de l'eau du cours d'eau (réalimentation induite).

L'objectif de cette étude est donc de déterminer les mécanismes hydrochimiques et biologiques à l'origine du phénomène, d'en déduire les possibilités d'amélioration du site et d'en tirer d'éventuelles mesures préventives, applicables à l'implantation de nouveaux captages.

Dans ce but ont été menées :

- une étude des mécanismes hydrogéologiques du site avant et après exploitation du champ captant ;

- une étude des mécanismes physico-chimiques ;

- une étude microbiologique des eaux concernées.

Avant de développer ces points, il peut être utile de rappeler les propriétés du manganèse dans l'eau.

\section{Le problème du manganèse dans les eaux}

Le manganèse est présent en solution dans les eaux naturelles sous sa forme réduite (MnII), ionique $\left(\mathrm{MN}^{2+}\right)$ ou complexée $\left(\mathrm{Mn} \mathrm{SO}_{4}{ }^{\circ}\right.$ et complexes organiques). En milieu oxydant, il précipite sous forme d'oxyde $\mathrm{Mn} \mathrm{O}_{2}$. En milieu réducteur, il précipite à $\mathrm{pH}$ alcalin sous forme de carbonate (rhodocrosite) comme le montre le diagramme pE-pH (Fig. 1).

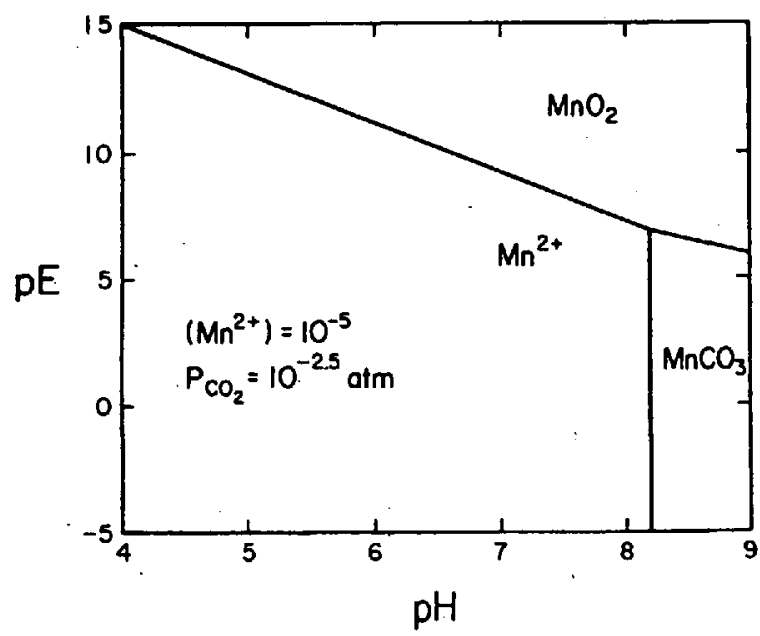

Fig. 1. Diagramme pE-pH du manganèse (Sposito 1989).

Fig. 1. A pE-pH diagram for manganese (Sposito 1989).

Aux $\mathrm{pH}$ rencontrés dans les eaux naturelles, l'oxydation de $\mathrm{Mn}^{2}+$ est un phénomène lent en raison de la forte énergie d'activation (Stumm \& Morgan 1981 ) et sa présence pose donc des problèmes pour la potabilisation des eaux. A des $\mathrm{pH}$ supérieurs a 9, l'oxydation devient autocatalytique (exponentielle en fonction du temps). Sinon, des catalyseurs deviennent nécessaires et les plus actifs sont les microorganismes comme l'ont montré les expériences en présence d'inhibiteurs d'activité biologique (Nealson et al. 1988).

L'oxydation du manganèse réduit peut être indirecte, liée aux modifications de $\mathrm{pH}$ et Eh engendrées par l'activité photosynthétique (Algues, Macrophytes) ou liée à des protéines catalytiques chez les Bactéries Bacillus SG-1, Leptothrix discophora, Pseudomonas S3-6 (revue dans Nealson et al. 1988). L'utilisation énergétique de la réaction étant rarement démontrée, on suppose qu'elle joue un rôle dans la détoxication des peroxides ou superoxides.

La réaction inverse, c'est-à-dire la réduction de Mn (IV), s'accompagne de la solubilisation du manganèse. Elle peut être indirecte, liée aux diminutions de $\mathrm{pH}$ et Eh ou aux métabolites résultant de l'activité bactérienne : $\mathrm{H}_{2} \mathrm{~S}$, oxalate et autres acides organiques (Stone \& Morgan 1984), $\mathrm{H}_{2} \mathrm{O}_{2}$ (Ghiorse 1988). Cependant, le rôle de Mn (IV) comme accepteur d'électron (réduction directe) a été démontré chez de nombreuses bactéries (Lovley 1991). 
La réduction nécessite souvent un contact direct avec les cellules des microorganismes mais il existe des molécules dialysables catalysant la réduction (DiRuggiero \& Gounot 1990). Enfin, certaines souches peuvent oxyder ou réduire le manganèse selon les conditions de potentiel redox (Gounot et al. 1988).

Lors de la potabilisation des eaux (concentration maximale admissible $0,05 \mathrm{mg} . \mathrm{l}^{-1}$, l'élimination du manganèse par voie physico-chimique réclame l'utilisation d'un oxydant (ozone, bioxyde de chlore, permanganate), l'aération étant insuffisante.

L'oxydation biologique peut être obtenue en station hors-sol (Mouchet et al. 1985) ou par injection d'eau aérée dans la nappe (Bernard \& Sérieys 1986, Braester \& Martinell 1988).

Il s'agit là de mesures curatives. Peut-on mettre en place des mesures préventives?

\section{Contexte géographique et hydrogéo- logique}

La ville de Capdenac-Gare (Fig. 2), située sur la rive gauche du Lot, est construite principalement sur les alluvions des première (Fy, ensemble alluvial de bas niveau) et seconde terrasses ( $F x$, complexe alluvial de haut niveau) du Lot (Fig. 3). Au SudEst et sur la rive droite du Lot, affleurent les formations sur lesquelles reposent les alluvions : argiles à graviers de l'Eocène (e 6-7), calcaires dolomitiques et argilites vertes du Lias (1), grès du Trias (t) et diorite quartzique (n2).

La basse plaine ( $\mathrm{Fz}$, alluvions de basse plaine) - « las Fargues » - s'étend au Nord de la gare et de la ligne de chemin de fer. Autrefois essentiellement agricole et inondable, ce secteur tend à devenir une zone artisanale et industrielle du fait de la place disponible et de la maîtrise des crues du Lot par l'action des barrages.

La portion du Lot concernée est comprise entre deux sites de micro-centrales. Ainsi, l'aménagement du site aval (altitude de la chaussée : 166m NGF) et son fonctionnement (débits prélevés) conditionnent quasi-continuellement le niveau du plan d'eau de la rivière dans la zone étudiée. De plus, les différents barrages en amont du site régularisent les débits de la rivière tant ent été qu'en hiver. Sauf lors de crues exceptionnelles qui ne sont que partiellement écrêtées, le niveau du Lot, situé entre $3,50 \mathrm{~m}$ et 4,00 $\mathrm{m}$ au-dessous de la surface de la plaine, déborde rarement du lit mineur.

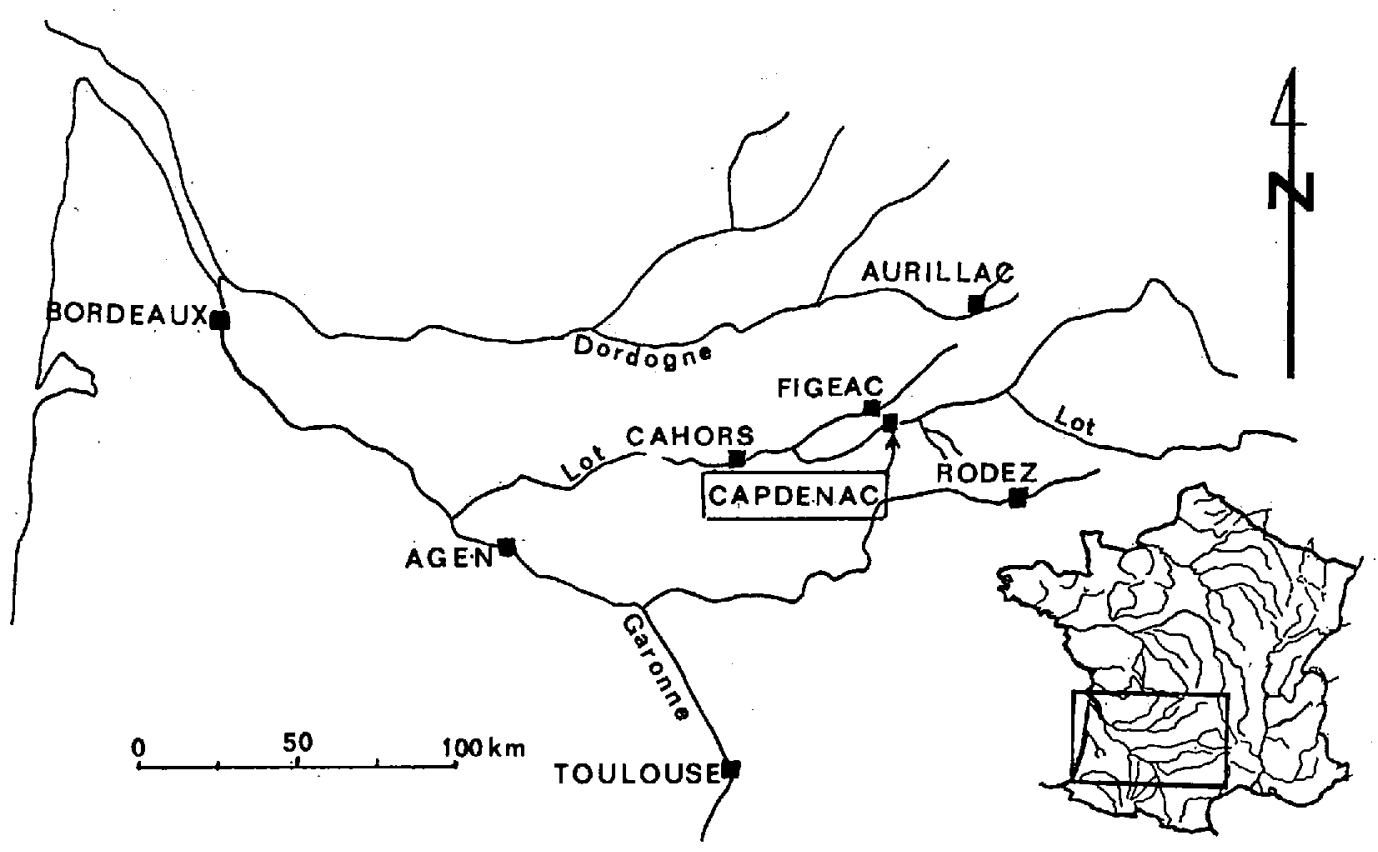

Fig. 2. Localisation du champ captant de Capdenac-Gare.

Fig. 2. Location of the well field of Capdenac-Gare. 


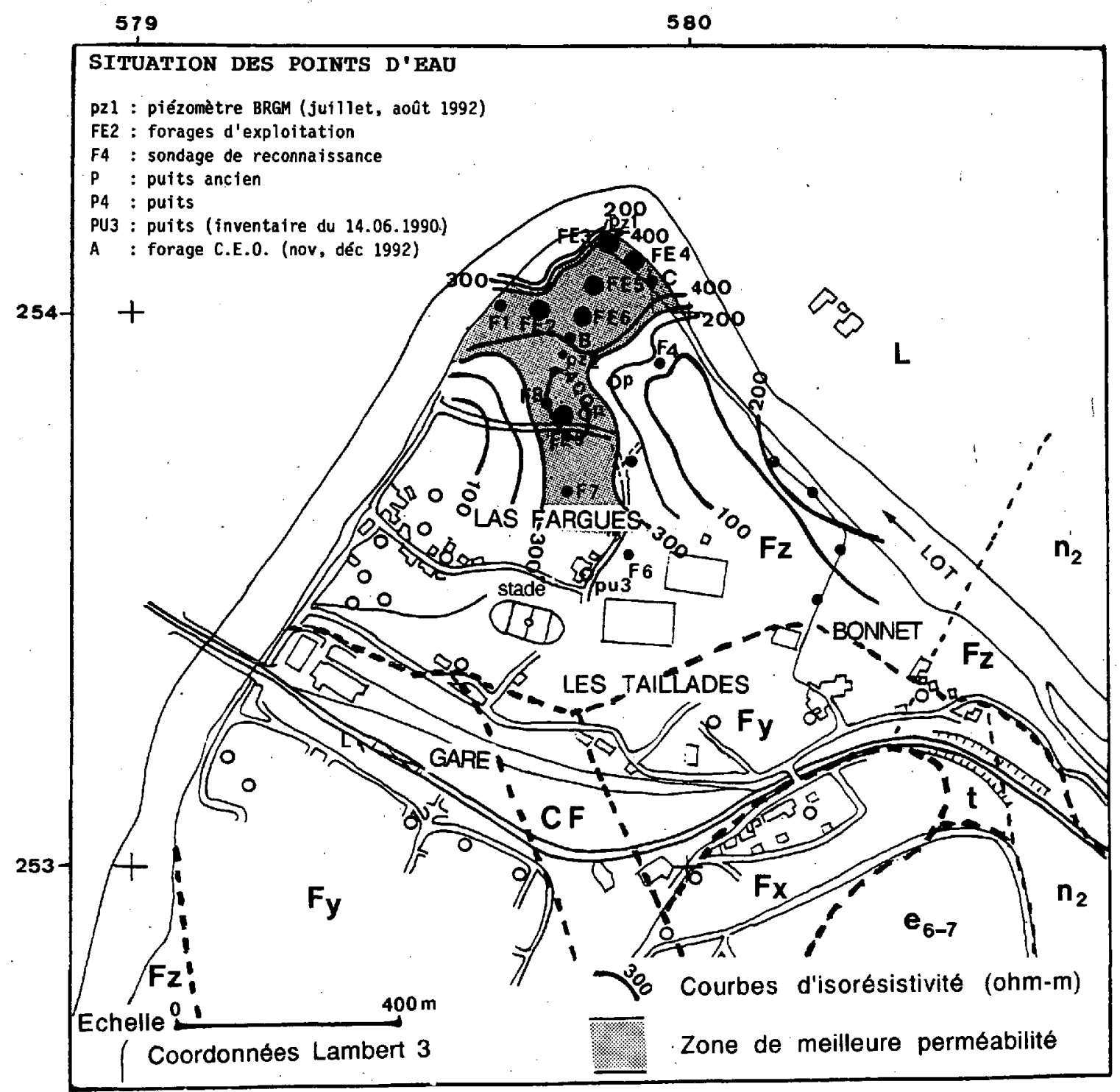

Fig. 3. Situation des points d'eau et zone de meilleure perméabilité.

Fig. 3. Location of the well sites and the better hydraulic conductivity zone.

La structure hydrogéologique du champ captant est bien connue à partir des ouvrages qui l'équipent (puits, forages, sondages, piézomètres). Leur situation et les résultats essentiels de la prospection géophysique par sondages électriques sont présentés sur la figure 3 ; elle met en évidence une zone de bonne perméabilité des alluvions et un secteur plus résistant (argiles, vases...) notamment entre les forages FE3,
FE1 et la rive du Lot, zone où les faibles vitesses de l'eau favorisent la sédimentation de fines particules.

Les relations entre le champ captant, la nappe et le Lot ont été précisées par des pompages préalables au niveau de F10, F3, F9, F7 et F8 et par les résultats d'enregistrement des niveaux de la nappe et de la rivière (Fig. 4) : 


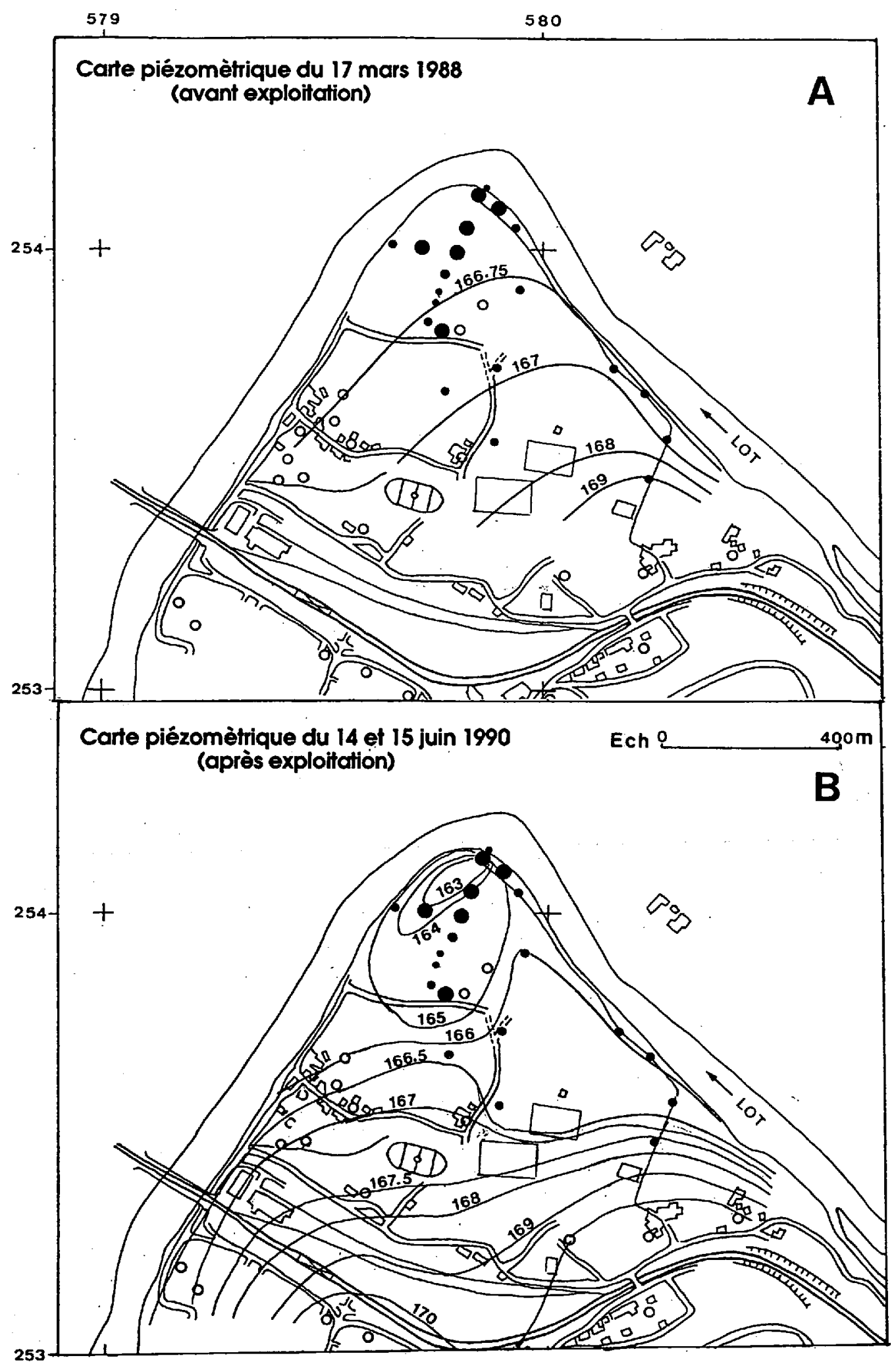

ézomètrique du 17 mars 1988 ovant exploitation) 
- l'influence hydraulique du champ captant s'étend sur l'ensemble de la nappe ;

la nappe alimente le champ captant au niveau du secteur du sondage $F 7$ (carte piézomètrique de juin 1990) sur un front de $200 \mathrm{~m}$ environ ; le débit d'alimentation peut être évalué à $40 \mathrm{~m}^{3} / \mathrm{h}$, en prenent $\mathrm{T}=10^{-2} \mathrm{~m}^{2} / \mathrm{s}, \mathrm{i}=0,006$ et $1=200 \mathrm{~m}$. Bien entendu ce débit calculé varie dans le temps en fonction de l'alimentation de la nappe par les coteaux ;

- le Lot alimente le champ captant à travers ses berges et les alluvions qui jouent le rôle de filtre.

\section{Matériels et méthodes d'étude}

\subsection{Origine des échantillons et méthodes de prelèvement}

Les échantillons d'eau ont été prélevés au niveau de chaque puits en exploitation, dans deux piézomètres proches du champ captant et également dans le Lot, à hauteur de ce champ captant. Les prélèvements étaient mensuels.

Au niveau des forages, les prélèvements ont été effectués quand le forage était en pompage. Un tuyau (type tuyaụ d'arrosage) était installé au niveau d'un robinet donnant directement sur la colonne d'eau. Il permettait de faire couler l'eau en permanence dans un seau pendant au moins 15 minutes avant l'échantillonnage proprement dit.

Deux sortes d'échantillonnages étaient pratiqués :

- pour les analyses physico-chimiques sur place et au laboratoire, les échantillons ont été prélevés dans des flacons en polyéthylène ou en verre nettoyés au mélange sulfo-chromique et transportés en caissons isothermes à environ $+4^{\circ} \mathrm{C}$;

- pour les analyses microbiologiques, les échantillons d'eàu ont été transvasés dans des flacons stériles et transportés au laboratoire en caisson isotherme a environ $+4^{\circ} \mathrm{C}$.

Dans les piézomètres, les prélèvements se faisaient de la même manière après avoir pornpé l'eau pendant au moins 20 minutes, afin de renouveler l'eau.

\subsection{Analyses physico-chimiques}

Les paramètres mesurés correspondent :

- aux besoins élémentaires des microorganismes : la source de carbone (carbone organique dissous), les sources d'azote ( $\mathrm{NH}^{4+}, \mathrm{NO}^{3-}$;
- à leurs conditions de vie : température, $\mathrm{pH}$, potentiels d'oxydo-réduction, oxygène ;

- aux résultats de leur activité : manganèse et fer solubles, nitrites, nitrates, ammoniaque, bicarbonate.

La conductivité permet d'évaluer la minéralisation globale de l'eau et les concentrations en $\mathrm{Cl}-$ et $\mathrm{SO}$ - permettent de repérer des eaux de minéralisations différentes.

Ont été mesurés in situ :

- la température et la concentration en oxygène dissous à l'aide d'un oxymètre W.T.W. dont la sonde était posée à la sortie du tuyau dans le seau (lecture faite après un temps de 5 à 10 minutes permettant à la sonde de se stabiliser);

- le pH avec un pH-mètre W.T.W. pH 196T (électrode TA-pH/T) dans les mêmes conditions ;

- le potentiel d'oxydo-réduction avec un multimètre Micronta 22-185., dans les mêmes conditions. L'électrode à potentiel rédox (référence calomel) est étalonnée dans une solution tamponnée de fer fẹrrique/ferreux ;

- la conductivité, dans des conditions identiques, à l'aide d'un conductimètre W.T.W.

Au laboratoire ont été effectués :

- le dosage de l'alcalinité (fait le jour même du prélèvement ou le lendemain au plus tard) grâce à un titreur automatique ;

- le dosage de la chlorophylle (uniquement pour le Lot) fait suivant la méthode d'extraction à l'éthanol chaud ;

- le dosage de l'azote ammoniacal par colorimétrie au bleu d'indophénol ;

- le dosage des nitrates et nitrites par chaîne Technicon en flux continu. Les nitrates sont réduits en nitrites par passage dans une colonne réductrice cadmium-cuivre ;

- le dosage du carbone organique total, des chlorures, du fer, du manganèse et des métaux lourds par le BRGM d'Orléans.

\subsection{Analyses microbiologiques}

Des observations au microscope optique de microorganismes ont été effectuées à partir de cultures réalisées sur un milieu pour Leptothrix (Mulder \& Van Veen 1972) et sur un milieu, pour bactéries hétérotrophes, au citrate ferrique (Clark et al. 1967). 
Pour chaque dilution, deux répliques ont été faites et mises à incuber à $12^{\circ} \mathrm{C}$ et à $20^{\circ} \mathrm{C}$.

Des échantillons d'eau fixés au formaldéhyde à $2 \%$ ou au glutaraldéhyde ont été observés au microscope électronique à transmission.

Les bactéries sont dénombrées par microscopie en épifluorescence (DAPI). Les biovolumes des bactéries sont estimés à partir de photographies et convertis en $\mu \mathrm{g}$ de carbone par litre à partir des données de Simon \& Azam (1989).

La production bactérienne a été estimée in situ par incorporation de thymidine tritiée (Fuhrman \& Azam 1982) ou de leucine tritiée (Servais \& Lavandier 1993).

\section{Résultats}

\subsection{Caractéristiques physico-chimiques de la nappe}

\subsubsection{Températures}

L'histogramme (Fig. 5) montre l'évolution des températures dans la nappe et le Lot.

Le Lot, soumis directement aux conditions climatiques régionales, constitue un pôle à variabilité thermique importante, de $5.2^{\circ} \mathrm{C}$ en février à $19.9^{\circ} \mathrm{C}$ en juillet soit $14.7^{\circ}$ d'amplitude ; à l'opposé, la température de la nappe (FE9) ne varie que de $12.6^{\circ} \mathrm{C}$ en juin et $13.6^{\circ} \mathrm{C}$ en novembre soit une variation de $1.0^{\circ} \mathrm{C}$.

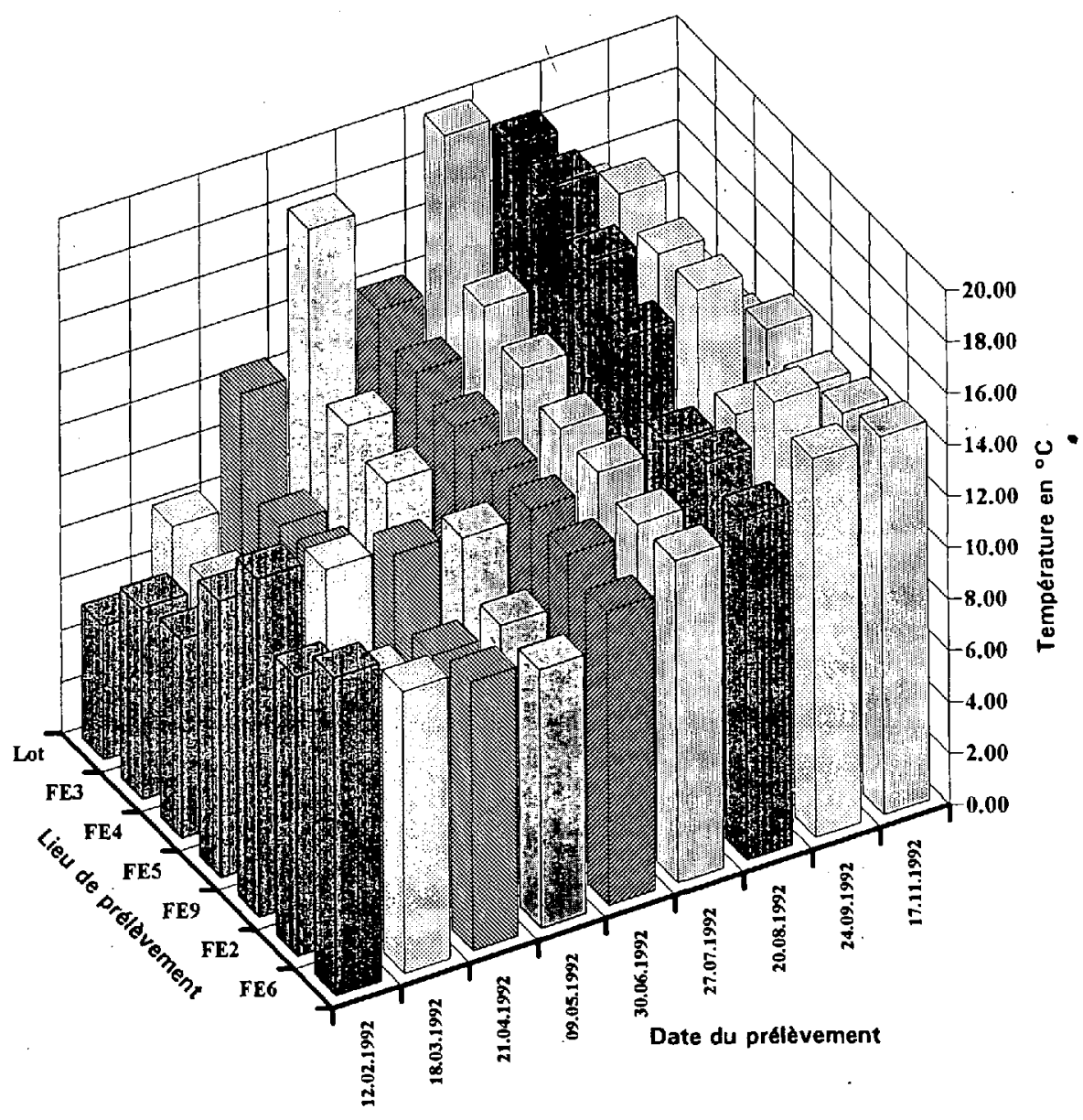

Fig. 5. Histogramme des températures dans le Lot et les forrages en 1992.

Fig. 5. Histogram of the water temperatures in the Lot river and the wells during 1992. 
Les températures de l'eau des forages sont d'autant plus influencées par les variations saisonnières que leur situation est proche du Lot. Leurs variations dans le temps se font avec un retard de 1 à 4 mois selon l'éloignement de la berge.

\subsection{2. $p H$}

Le $\mathrm{pH}$, stable au cours des campagnes, est proche de la neutralité dans la nappe. L'eau des forages des berges est cependant plutôt alcaline ( $>7)$ tandis que celle des forages FE9, F5 et F6 est plutôt acide $(<7)$. L'eau du Lot est nettement alcaline $(7.50<\mathrm{pH}<8.98)$.

On a donc un pôle rivière alcalin avec le Lot et un pôle nappe plutôt acide.

\subsubsection{Conductivité}

On distingue deux pôles de valeurs de conductivité : le pôle Lot (de 97 à $197 \mu \mathrm{S} / \mathrm{cm}$ ) et le pôle FE9 (de 476 a $549 \mu \mathrm{S} / \mathrm{cm}$ ). Les valeurs importantes mesurées en $\mathrm{F} 6(1230 v \mathrm{~S} / \mathrm{cm})$ résultent probablement de foyers anthropiques de pollution en amont.

La conductivité de l'eau des forages varie en fonction du taux de mélange des eaux en provenance des deux pôles mais aussi en fonction de phénomène de dissolution des carbonates en bicarbonates.

\subsubsection{Sulfates et chlorures}

Les concentrations en sulfates dans les forages et dans le Lot sont de l'ordre de $10 \mathrm{mg} / \mathrm{l}$ tout au long de l'année. Cependant de fortes concentrations sont rencontrées au niveau des forages pz2, FE9 (de 30 à $50 \mathrm{mg} / \mathrm{l}$ ) et surtout en F5 et F6 (de 100 à $200 \mathrm{mg} / \mathrm{l}$ ).

Les concentrations en chlorures les plus élevées sont mesurées au niveau des forages pz2, FE9 (de 15 à $20 \mathrm{mg} / \mathrm{l}$ ) et surtout $\mathrm{F} 6$ où elles atteignent 140 $\mathrm{mg} / \mathrm{l}$; comme celles des sulfates, ces fortes valeurs témoignent sans doute d'une pollution de la nappe.

\subsubsection{Carbone organique dissous (C.O.D.)}

On distingue deux pôles très marqués de concentration en C.O.D. : le pôle Lot (de 2,6 d $4,4 \mathrm{mg} / \mathrm{l}$ ) et le pôle FE9 (pôle nappe) de 0,5 à 1,0 mg/l (Fig. 6).

Il se produit un abattement important du C.O.D. entre le Lot et lä nappe, mäis cet abattement se produit essentiellement au niveau de la berge (FE3 et FE4).

\subsubsection{Oxygène dissous}

Les valeurs maximales de l'eau du Lot accusent une légère diminution en été de $12 \mathrm{mg} / 1$ à $8 \mathrm{mg} / 1$, liée à la température (Fig. 7). Les valeurs moyennes $(5 \mathrm{mg} / \mathrm{l})$, plutôt stables, des eaux des forages pz2, FE9, F5 caractérisent la nappe.

Au niveau des forages FE2 et FE6 les concentrations en $\mathrm{O}_{2}$ dissous de l'eau prélevée sont toujours très faibles ; elles seraient certainement voisines de zéro sans la légère réoxygénation qui s'opère probablement lors du relevé. L'eau des forages situés entre le Lot et FE6 accuse une diminution des teneurs en oxygène dissous (liée à la consommation bactérienne tandis qu'en FE6 et FE9 les concentrations augmentent par réoxygénation à partir de la surface.

Dans le forage $\mathrm{F} 6$, les teneurs en $\mathrm{O}_{2}$ sont plus faibles que dans les autres forages représentatifs du pôle nappe ; elles reflètent la pollution que suggéraient déjà les concentrations en chlorures et sulfates.

\subsubsection{Potentiel d'oxydo-réduction, Eh}

Les mesures du potentiel d'oxydo-réduction sont corrélées à celles de l'oxygène dissous dans l'eau. Les valeurs les plus faibles sont mesurées en FE2 et FE6 (340 mv), les plus fortes dans le Lot et le pôle nappe en hiver $(470 \mathrm{mv})$.

Globalement les valeurs diminuent de l'hiver vers l'été.

\subsubsection{Manganèse dissous}

Les concentrations les plus élevées ont été mesurées dans les eaux de FE2 et FE6 : de $828 \mu \mathrm{g} / 1$ à $1346 \mu \mathrm{g} / 1$ en FE2, de $233 \mu \mathrm{g} / 1$ à $467 \mu \mathrm{g} / 1$ en FE6 (Fig. 8).

Dans les autres forages, les concentrations dépassent rarement la concentration maximale tolérée de $50 \mu \mathrm{g} / 1$. La production de Mn dissous se situe d'août à novembre en FE3 et FE4 forages situés tout près de la berge.

Dans l'eau du Lot, le manganèse, comme le fer, est sous forme complexée ou particulaire très fine étant donné la valeurs du potentiel rédox.

\subsection{9.-Nitrates, nitrites et ammonium}

Nous n'avons pas décelé de nitrites. Les nitrates en revanche sont présents, surtout au niveau des puits 


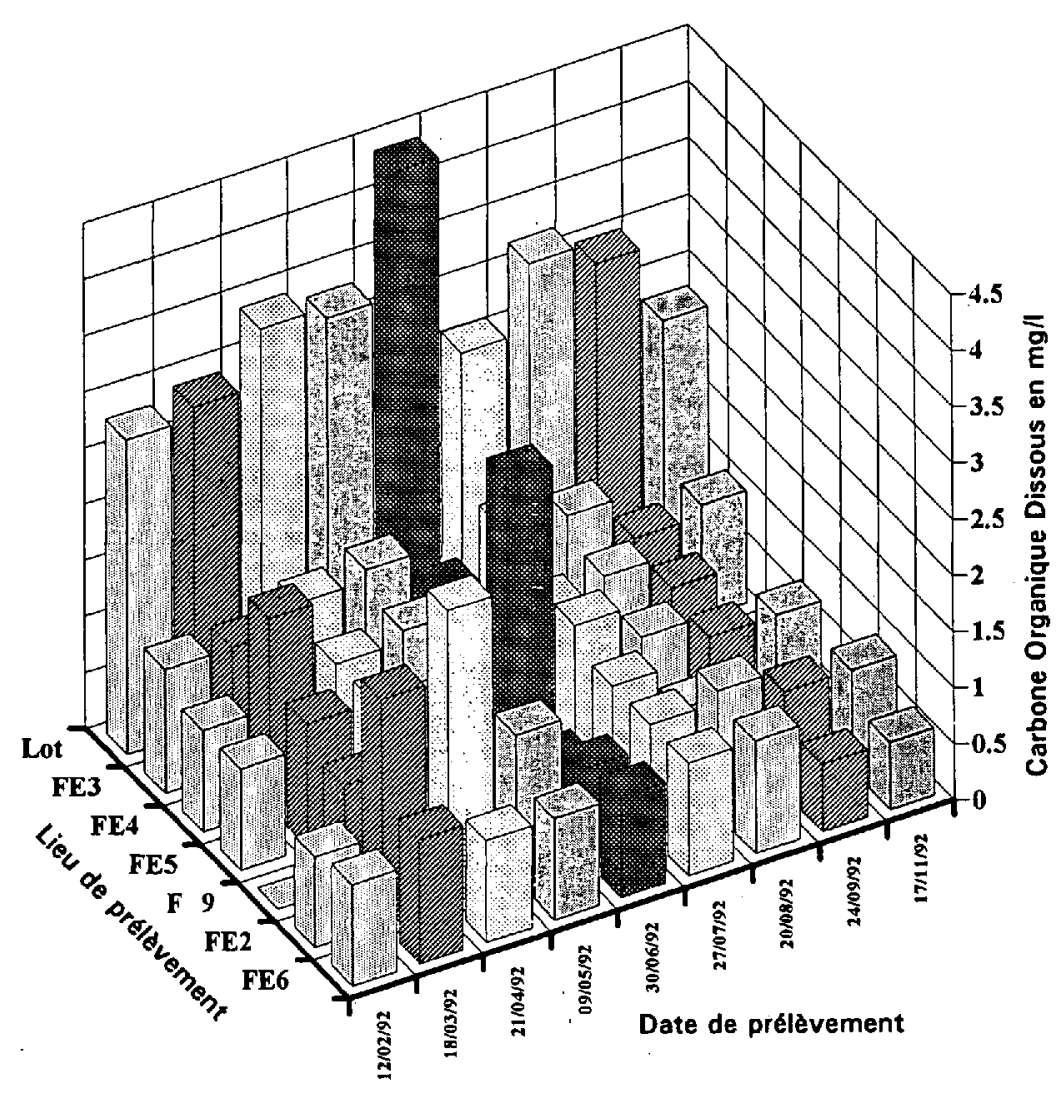

Fig. 6. Evolution des concentrations en carbone organique dissous (C.O.D.) dans le Lot et les forrages en 1992.

Fig. 6. Variations of the dissolved organic carbon (C.O.D.) concentrations in the waters of the Lot river and the wells during 1992.

pz2, FE9, F5 et F6 alimentés par les coteaux, mais à des taux toujours très inférieurs à la norme préconisée $(50 \mathrm{mg} / \mathrm{l})$. Les concentrations en nitrates dans les autres forages et dans le Lot sont faibles et inférieures à $5 \mathrm{mg} / 1$; elles sont nulles lorsque le manganèse est présent.

L'ion ammonium est toujours fortement représenté en FE2 et FE6. Dans les autres forages, sa concentration a tendance à augmenter avec la saison chaude et avec la diminution des ions nitrates ; sa présence est donc liée à l'anaérobiose, soit par absence de nitrification, soit par réduction dissimilative.

\subsubsection{Pigments photosynthétiques}

La concentration en chlorophylle augmente fortement pendant les mois de juin et juillet. Un fort pic de phéopigments est apparu lors de la campagne de mai en liaison avec une forte crue du Lot (Tableau I).

\subsection{Analyses microbiologiques}

\subsubsection{Observations}

La mise en culture d'échantillons d'eau provenant des forages FE2 et FE6 dans le milieu au citrate ferrique pour bactéries hétérotrophes (Clark et al. 1967), n'a pas permis d'obtenir un développement bactérien. Par contre, dans le milieu pour Leptothrix des bactéries ont pu être observées au microscope à immersion entre 8 jours de culture. Elles se développent en plus grand nombre à $12^{\circ} \mathrm{C}$ qu'à $20^{\circ} \mathrm{C}$ mais sont en revanche de plus grande taille à $20^{\circ} \mathrm{C}$.

Tous les micro-organismes observés étaient gram - , ce qui est normal pour des bactéries d'eau naturelle. 


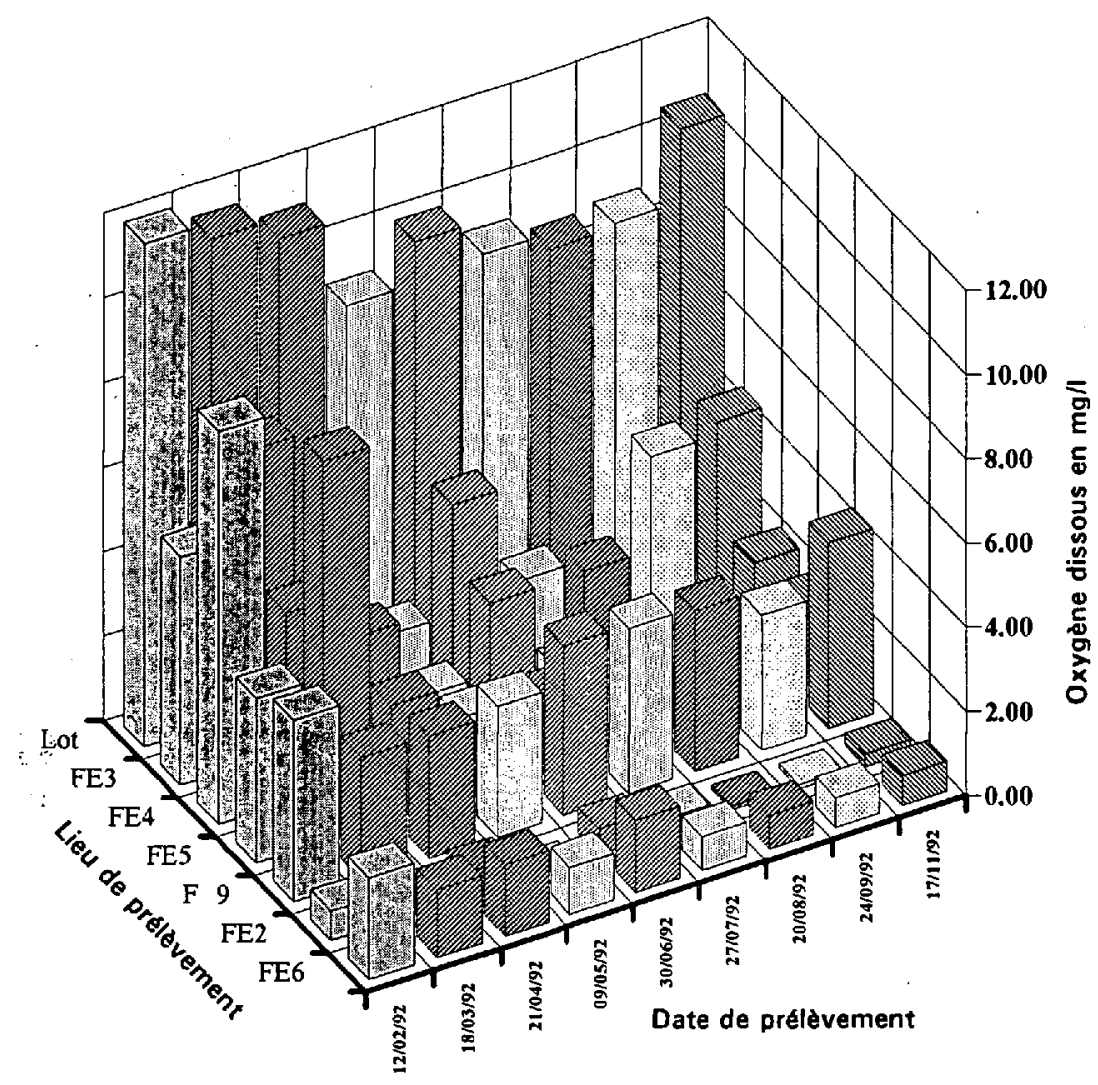

Fig. 7. Evolution de l'Oxygène dissous dans le Lot et les forages en 1992.

Fig. 7. Variations of dissolved oxygen content in the waters of the Lot river and of the wells during 1992.

Tableau 1. Evolution de la concentration en chlorophylle et phéopigments lors des campagnes en 1992.

Table 1. Variations of the concentration of chlorophyll and pheopigments during the 1992 campaigns.

\begin{tabular}{|c|c|c|c|}
\hline Campagne & Chlorophylle & Phéopigments & Total \\
\hline & $\mu \mathrm{g} .1^{-1}$ & $\mu \mathrm{g} \cdot 1^{-1}$ & $\mu g \cdot 1^{-1}$ \\
\hline $12 / 02 / 92$ & 5,21 & 1,44 & 6,65 \\
\hline $18 / 03 / 92$ & 5,54 & 3,45 & 8,99 \\
\hline $21 / 04 / 92$ & 8,41 & 1,52 & 9,33 \\
\hline $09 / 05 / 92$ & 8,83 & 13,70 & 22,53 \\
\hline $30 / 06 / 92$ & 15,43 & 5,78 & 21,21 \\
\hline $27 / 07 / 92$ & 16,53 & 5,30 & 21,83 \\
\hline $20 / 08 / 92$ & 9,08 & 2,70 & 11,78 \\
\hline $24 / 09 / 92$ & 5,60 & 5,40 & 11,00 \\
\hline
\end{tabular}




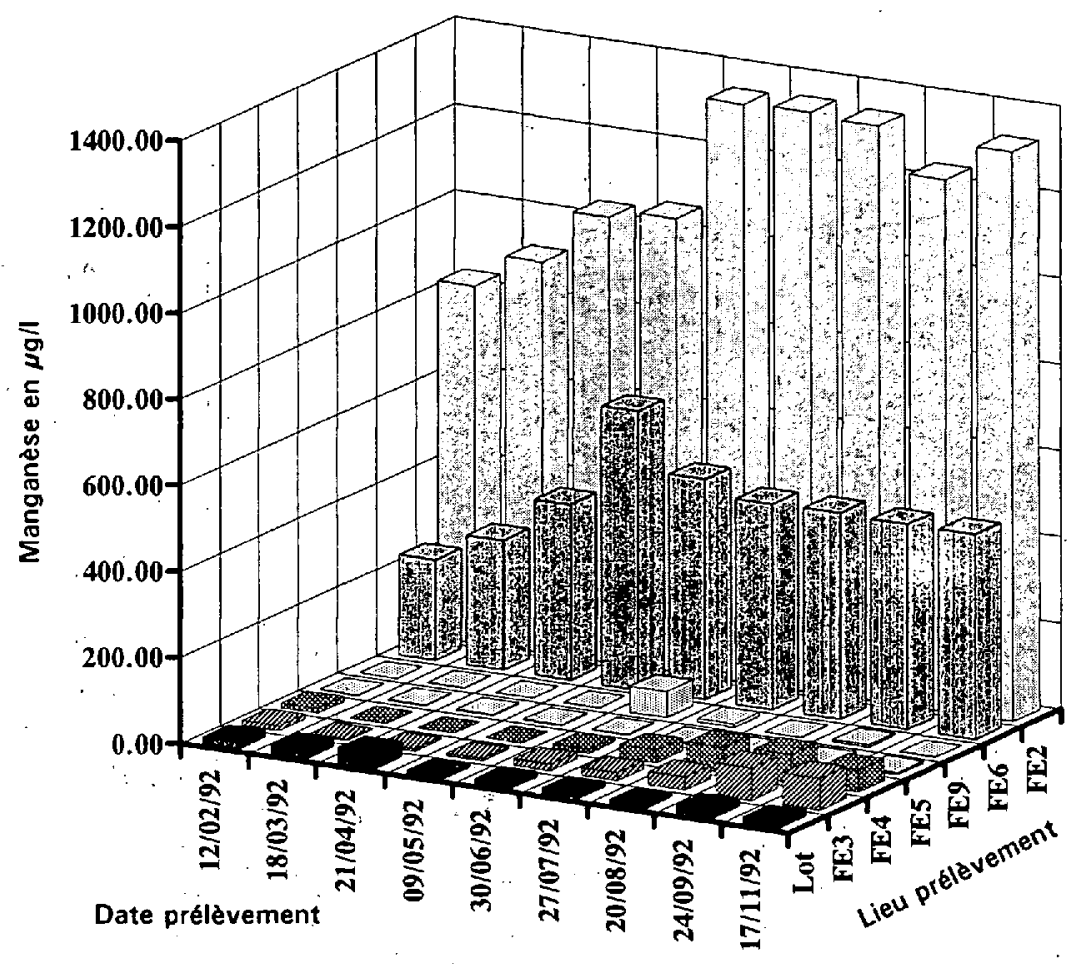

Fig. 8. Evolution des concentrations en manganèse dissous dans le Lot et les forages en 1992.

Fig. 8. Variations of the dissolved manganese concentrations in the waters of the Lot river and the wells during 1992.

Malgré un frottis énergique effectué lors du montage entre lame et lamelle des échantillons d'eau, les bactéries avaient tendance à rester en amas ; cependant aucune gaine n'a été observée.

Le nettoyage du forage FE6 par hydrojet au mois de mars a permis d'observer directement des bactéries fixées sur les tubages du puits. Ces bactéries étaient entourées d'un mucus blanchâtre abondant. Les observations au microscope électronique ont montré des bactéries coccoïdes indéterminées. Dans la bâche de reprise, les genres Crenothrix et Leptothrix sont bien représentés.

\subsubsection{Dénombrement bactérien et biomasse.}

La berge joue bien son rôle de filtre naturel car le nombre total bactérien est nettement plus fort dans le Lot que dans les forages (Fig. 9). Les densités et les biomasses bactériennes diffèrent nettement selon les puits mais on note une certaine homogénéité dans l'eau de nappe (puits F9, F4, F5 et F6).

Dans le Lot, les plus faibles valeurs s'observent en mai-juin (période de crue). Dans les puits aucune tendance saisonnière nette ne se dégage.

\subsubsection{Production bactérienne}

Les mesures d'incorporation de thymidine tritiée dans l'eau de nappe (F9) se sont révélées négatives ; en revanche, les taux d'incorporation de leucine tritiée (Tableau 2) conduisent à des valeurs de production bactérienne nettement plus fortes dans le Lot que dans l'eau de nappe ; elles sont encore plus faibles dans l'eau des forages. Il en résulte des temps de renouvellement théorique des populations bactériennes importants. 


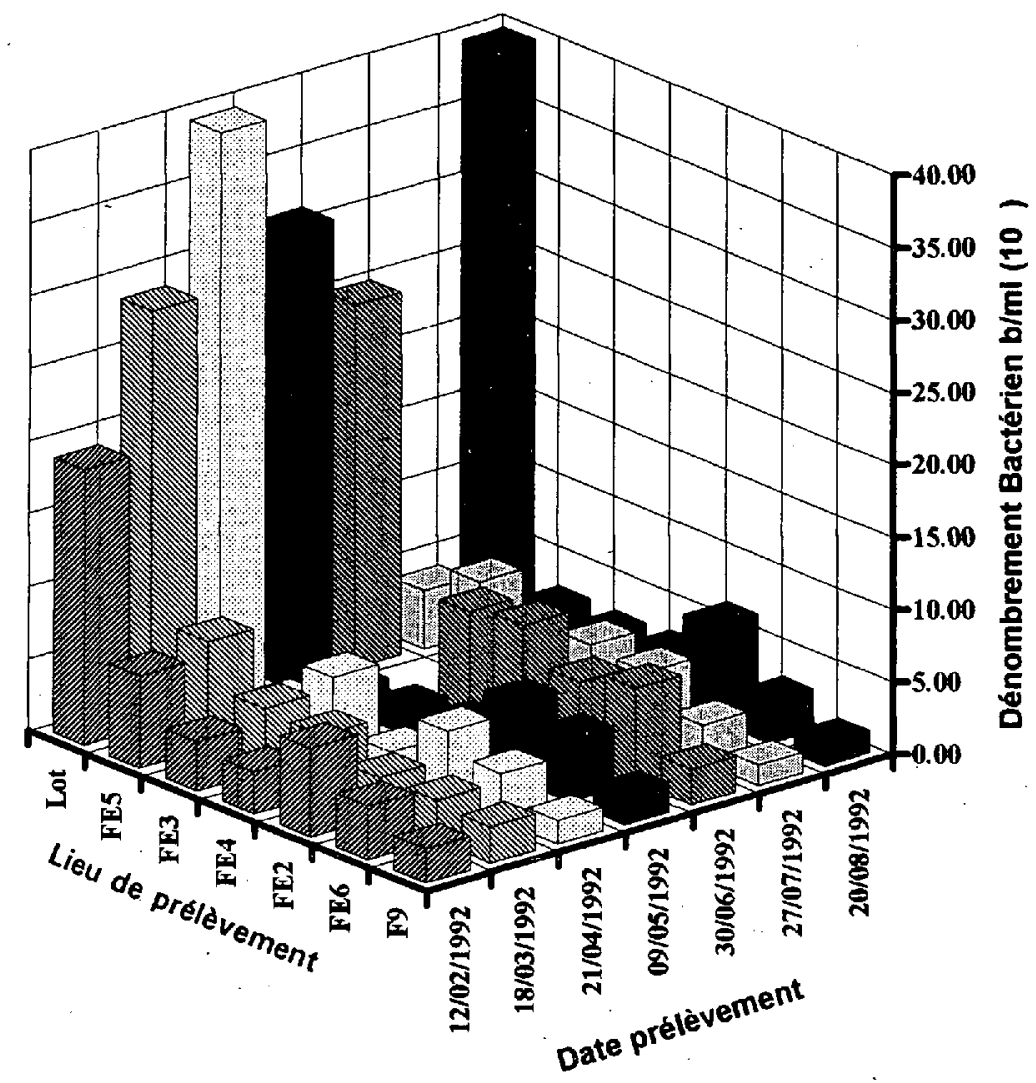

Fig. 9. Dénombrements bactériens dans les eaux du Lot et des forages en 1992.

Fig. 9. Bacterials numbers in the waters of the Lot river and the wells during 1992.

Tableau 2. Mesure de la vitesse réelle de synthèse protéique (Vp), production bactérienne (P.B.), temps de renouvellement théorique (temps) dans les forages et le Lot en juin 1992.

Table 2. Measure of true rate of proteic synthesis $(\mathrm{Vp})$, bacterial production ( $\mathrm{Pb}$ ), theoretical turn-over time (temps) in the wells and Lot river waters in June 1992.

\begin{tabular}{|c|c|c|c|c|}
\hline $06 / 1992$ & Lot & FE 3 & FE6 & FE9 \\
\hline \multicolumn{5}{|l|}{$v_{p}$} \\
\hline$\left(\right.$ nmol.1-1 $\left.h^{-1}\right)$ & $1,090.10^{-1}$ & $2,38 \cdot 10^{-3}$ & $1,67.10^{-3}$ & $8,60 \cdot 10^{-3}$ \\
\hline \multicolumn{5}{|l|}{ PB } \\
\hline$\left(\mu g C \cdot 1^{-1} \cdot h^{-1}\right)$ & 0,117 & $2,57.10^{-3}$ & $1,80 \cdot 10^{-3}$ & $0,92 \cdot 10^{-2}$ \\
\hline \multicolumn{5}{|l|}{ Temps } \\
\hline jours & 22 & 180 & 360 & 29 \\
\hline
\end{tabular}




\section{Discussion}

\subsection{Caractéristiques hydrodynamiques}

Avant la mise en route du champ captant, on constate que la nappe alimente le Lot (piézométrie de mars 88, Fig. 4 A). Les caractéristiques physicochimiques des forages, y compris ceux de la berge, FE3 et FE4, sont alors celles de l'eau de nappe en provenance des coteaux.

A partir du printemps 1989 le champ captant est exploité à $144 \mathrm{~m}^{3} / \mathrm{h}$ en moyenne et en juin 90 , un régime " d'équilibre hydrodynamique " s'est établi dans la nappe, offrant la configuration présentée sur la figure $4 \mathrm{~B}$. Cet « équilibre » instable ne résulte en fait que du gradient de la nappe dans sa zone amont non influencée par le pompage ; les autres paramètres sont en effet constants dans le temps y compris la cote du niveau du Lot qui est quasiment régulée par l'action des barrages en amont.

Ainsi, la configuration de la piézométrie dépendra uniquement du débit d'alimentation de la nappe par les coteaux, donc du régime pluviométrique. Ainsi, après les fortes pluies de septembre-octobre 92, la position géographique de la courbe piézométrique $167 \mathrm{~m} \mathrm{NGF}$, se situait très près du Lot, indiquant la plus forte alimentation de la nappe par les coteaux jamais mesurée.

La part relative des eaux du Lot et des eaux de nappe au niveau des forages peut être estimée à partir du bilan en chlorures, anion très stable, très peu réactif chimiquement et biologiquement.

Si X est la fraction d'eau pompée en provenance du Lot via les berges et la nappe, et $C$ la concentration en chlorure en $\mathrm{mg}^{-1}$, forage désignant ce qui a trait à l'eau d'un point de mesure et nappe, désignant ce qui a trait au pôle nappe (FE9), on peut écrire la relation suivante :

$$
\begin{aligned}
C \text { forage } & =X C \text { Lot }+(1-X) C \text { nappe } \\
X & =\frac{C \text { forage }-C \text { nappe }}{C \text { Lot }-C \text { nappe }}
\end{aligned}
$$

Le tableau III montre que les forages d'exploitation autres que FE9 pompent de l'eau originaire du Lot. Le calcul indique que l'eau pompée totale est issue à $22,5 \%$ d'eau de l'aquifère alluvial en provenance des coteaux et $\mathbf{a} 77,5 \%$ d'eau du Lot transitant par la nappe ; ce qui fait un débit de fourniture de $32,5 \mathrm{~m}^{3} / \mathrm{h}$ pour l'un et de $111,5 \mathrm{~m}^{3} / \mathrm{h}$ pour l'autre.

Le calcul n'est valable que si les concentrations en chlorures des eaux de la nappe (FE9) et du Lot sont constantes, tout au moins pendant le temps nécessaire au transfert des eaux du Lot vers le forage hydrauliquement le plus en aval (FE6). Cette hypothèse paraît justifiée par la constance des valeurs en chlorures mesurées à plusieurs années d'intervalle à la même saison dans le Lot et dans la nappe : 10,5 $\mathrm{mg} / 1$ de chlorure au FE9 en 1987 , contre 10,8 en 1990 ; entre 4 et $6 \mathrm{mg} / 1$ dans le Lot à une station proche (Bouillac) en automne 1987 contre $4 \mathrm{mg} / 1$ à Capdenac-Gare en automne 90 . Pendant l'été, toutefois, les teneurs en chlorures du Lot pourraient être sensiblement plus élevées (environ $8 \mathrm{mg} / \mathrm{l}$ en 1987 et en 1990).

\subsection{Caractéristiques physico-chimiques}

\subsection{1. pH, Eh et Manganèse}

Les valeurs de $\mathrm{pH}$ et Eh des différents forages et du Lot apparaissent figure 10.

Tableau 3. Calcul du pourcentage de mélange de l'eau du Lot et de la nappe pour les quatre premières campagnes.

Table 3. Calculated percentage of mixing between Lot river water and ground water for the four first campaigns.

\begin{tabular}{lccccc}
\hline & \multicolumn{5}{c}{ Pourcentage de mélange (Lot/Forages) } \\
\hline & FE2 & FE3 & FE4 & FE5 & FE6 \\
$12 / 02 / 92$ & 100 & 100 & 100 & 97,6 & 97,6 \\
$18 / 03 / 92$ & 100 & 93,1 & 100 & 100 & 93,1 \\
$21 / 04 / 92$ & 94 & 100 & 99 & 96 & 92 \\
$09 / 05 / 92$ & 97,3 & 100 & 99,1 & 99,1 & 94,7 \\
\hline
\end{tabular}



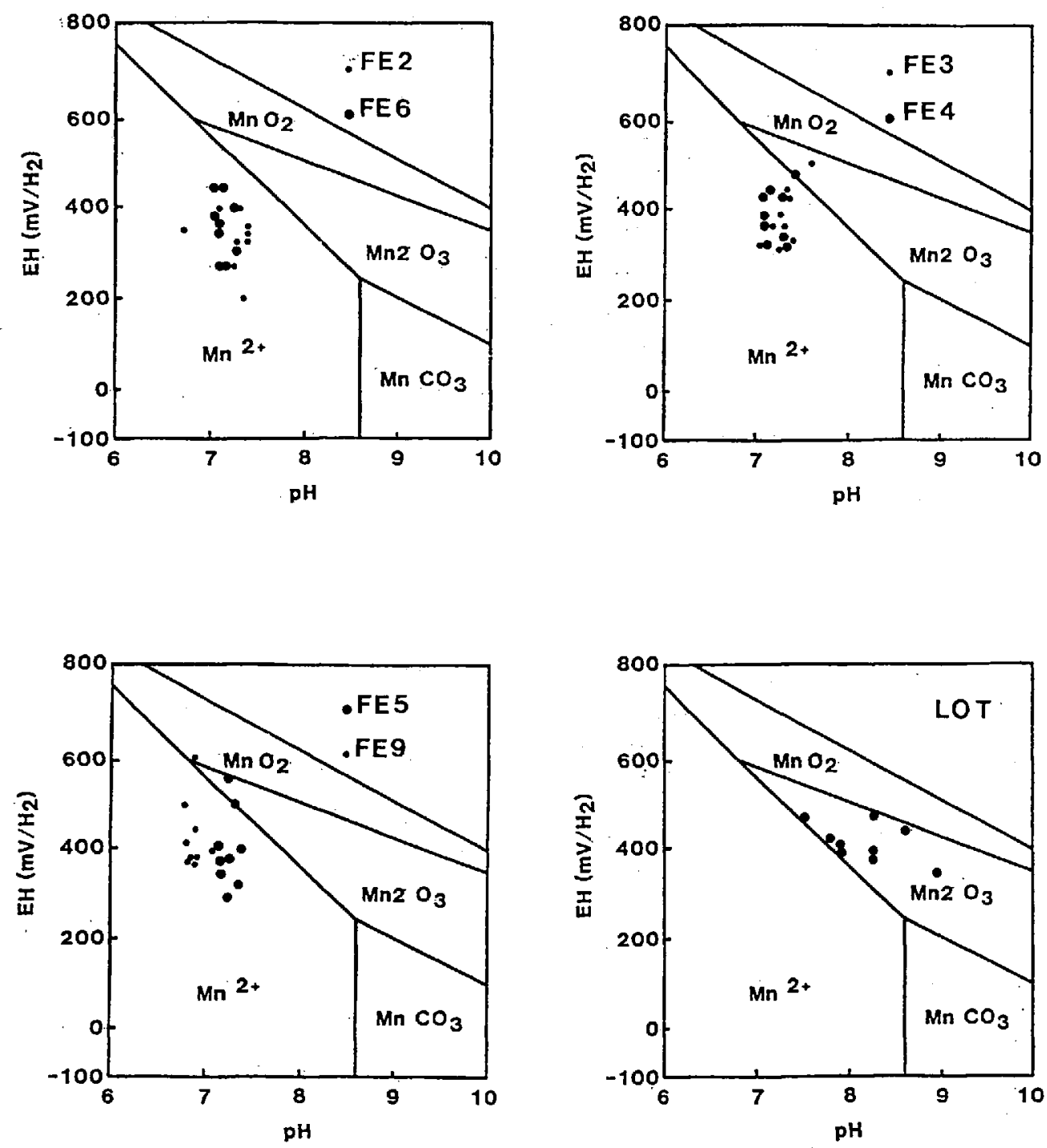

Fig. 10. Diagrammes Eh - pH du manganèse dans le Lot et les forages au cours de l'année 1992

Fig. 10. Eh-pH diagrams for manganese in the Lot river water and the wells during the year 1992

Le Lot, saturé en oxygène par la photosynthèse, est hors du domaine de stabilité de $\mathrm{Mn}^{2}+$ contrairement au pôle nappe (FE9) et FE5 en été où n'apparaît toutefois pas de manganèse en solution.

Les forages FE2 et FE6 ont été regroupés car ils se trouvent en permanence dans le domaine de stabilité de $\mathrm{Mn}^{2+}$ ce que confirment les fortes concentrations observées. Toutefois, le forage FE2 montre une augmentation de la teneur en manganèse au printemps sans relation avec le potentiel redox, phénomène déjà observé dans les nappes du Rhône par Mallessard (1983).

Les puits FE3, FE4 ont des comportements semblables : l'abaissement du potentiel redox en mai se traduit par l'apparition du manganèse en juin dans ces puits. Ceci ne se produit pas en FE5, ce qui 
montre d'une part que l'alimentation de ce dernier est indépendante de celle des puits FE3 FE4 et FE6 et, d'autre part, que l'abaissement de potentiel est nécessaire mais pas suffisant pour mobiliser le manganèse.

6.2.2. Oxygène, Carbone organique dissous, Température et Manganèse

L'eau du puits FE2 est dépourvue d'oxygène et de nitrate. Ce phénomène s'explique par le passage de l'eau pompée au travers de dépôts vaseux mịs en évidence lors du forage de FEl (Fig. 12), constatation qui avait entraîné l'abandon du puits pour l'exploitation. De faibles teneurs s'observent au niveau FE6; elles traduisent une légère réoxygénation de l'eau et amènent une oxydation du manganèse et de l'ámmonium (Fig. 11). Le processus est analogue à celui décrit dans la vallée du Rhône par Gounot \& Haroux (1986) et Gounot \& Di-Ruggiero (1991).

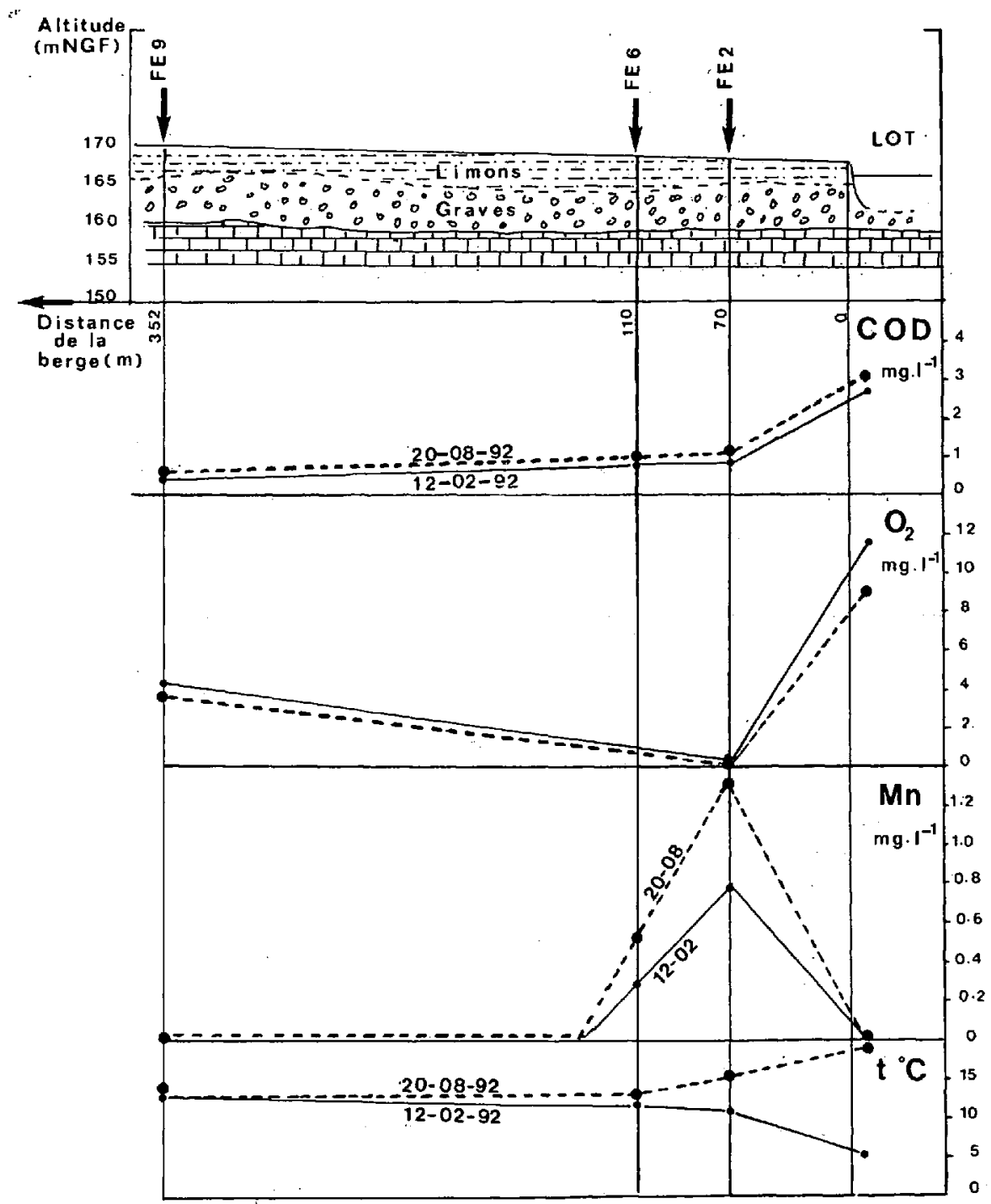

Fig. 11. Evolution de l'oxygène, du carbone organique dissous, du manganèse dissous et de la température le long d'un transect passant par des sédiments vaseux (effet de vase).

Fig. 11. Variations of dissolved oxygen, organic carbon, manganese concentrations and water temperatures along a muddy sediment cross-section (mud effect). 
Au cours de la saison, on observe en FE2 une corrélation linéaire de la concentration en manganèse avec la température du puits ( $r=0,73, n=9)$, meilleure qu'avec celle du Lot $(r=0,66, n=9)$. Cependant un cœfficient supérieur est obtenu si l'on prend la température du Lot du mois précédent $(r=0,83)$.

Plus complexe semble le fonctionnement des puits FE3 et FE4 situés près de la berge exposée au courant, dépourvue de dépôts vaseux dans le Lot ou les alluvions (Fig. 12).

En hiver, la berge semble jouer son rôle de filtre classique et il y a moins de manganèse dans les puits que dans l'eau du Lot. Au mois d'avril, on observe une augmentation du C.O.D. $\left(3,4 \mathrm{mg} / \mathrm{l}^{-1}\right)$ dans l'eau du Lot suivie en mai d'une chute de l'oxygène dans les puits ( $\left.<2 \mathrm{mg} .1^{-1}\right)$ et de l'apparition de manganèse en juin ( $>10 \mu \mathrm{g} .1^{-1}$ ) dans ces mêmes puits. Il semble que la consommation d' $\mathrm{O}_{2}$ (puis de $\mathrm{NO}_{3}{ }^{-}$) et de C.O.D. labile s'effectue au niveau de la berge. Cette hypothèse a été confirmée après l'implantation en août 1992 d'un nouveau piézomètre entre $\mathrm{FE} 3$ et la rive : la concentration en $\mathrm{O}_{2}$ y était de $0,3 \mathrm{mg} \cdot 1^{-1}$ contre $2,0 \mathrm{mg}$ en FE3 et 8,7 dans le Lot. On assiste ensuite à une réoxygénation de la nappe par la surface (la contribution de la nappe étant négligeable) sans doute suffisante pour que le manganèse précipite avant que l'eau ne parvienne en FE5. Ce schéma (Fig. 13), déjà décrit par Jacobs et al. (1988), ne s'applique toutefois qu'imparfaitement car les puits FE3 et FE4 fournissent encore une eau contenant du manganèse en Novembre alors que l'eau du Lot contient $10 \mathrm{mg} .1^{-1}$ d'oxygène et que le C.O.D. est aussi faible qu'en février.

Aucune corrélation linéaire (significative) ne peut être établie entre les différentes variables. Une corrélation satisfaisante $(r=0,614)$ apparaît entre le manganèse et la température de l'eau du Lot du mois précédent. Elle s'améliore avec une corrélation

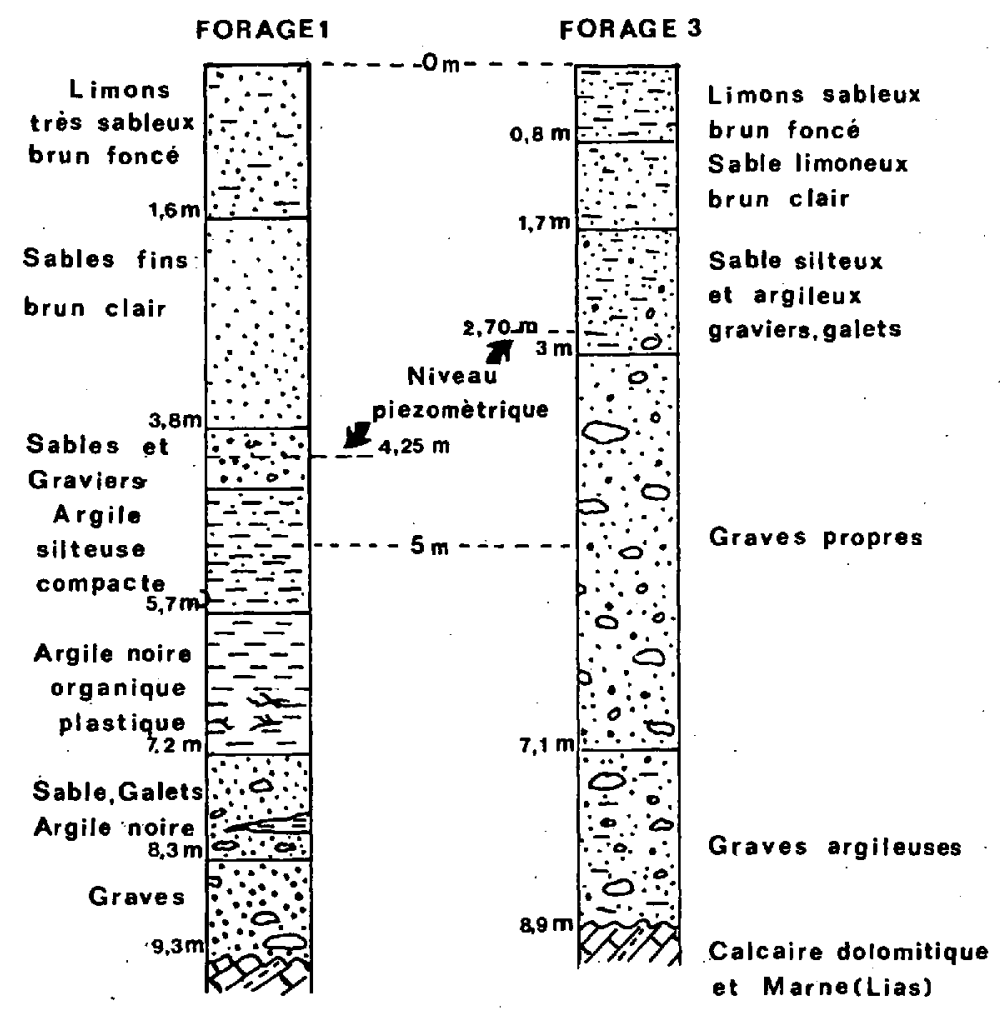

Fig. 12. Profils de forages effectués dans le champ captant (F. Bel, B.R.G.M.) : FE1 présence de vase enfouie, FE3 graves propres. Fig. 12. Vertical boring profiles in the well-field (F. Bel, B.R.G.M.) : FE1, hidden mud present ; FE3 clean gravels. 


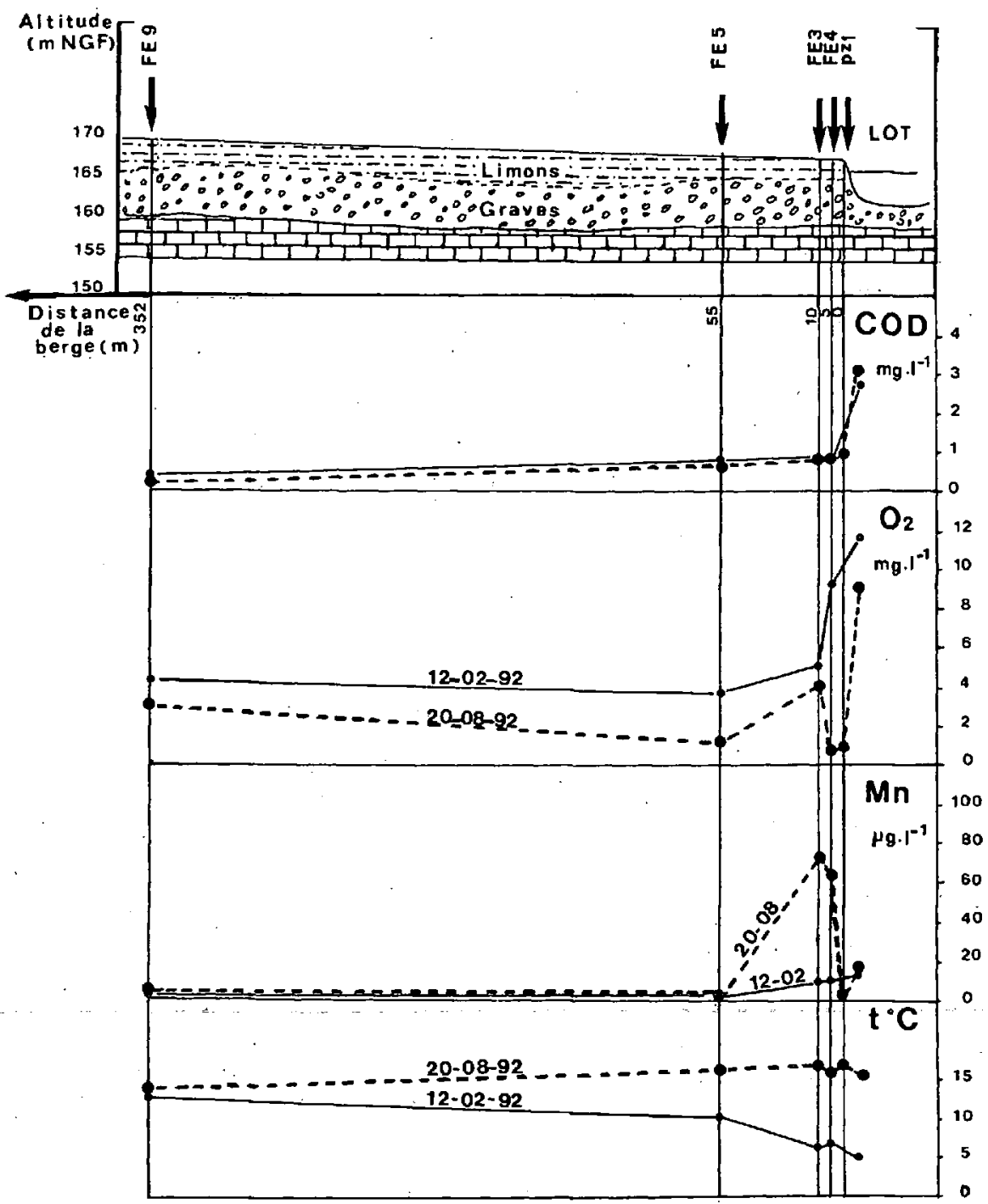

Fig. 13. Evolution de l'oxygène, du carbone organique dissous, du manganèse dissous et de la température le long d'un transect passant par des sédiments non vaseux (effet de berge).

Fig. 13. Variations of dissolved oxygen, organic carbon, manganese concentrations and water temperatures along a non-muddy sediment cross-section (riverbank effect).

exponentielle $(r=0,796)$ ce qui est logique du point de vue thermodynamique.

Il apparaît donc qu'il s'agit d'un phénomène se produisant au contact de l'eau du Lot (berge) dont les effets sont sensibles environ 1 mois plus tard au niveau des puits FE3 et FE4. On peut supposer que même en présence d'oxygène dans l'eau, la forte activité biologique entraîne des conditions réductrices au contact biofilm-substrat riche en manganèse (alluvions issues du permo-trias). Un processus analogue s'observe dans le cas de la dénitrification au niveau de l'épilithon des galets au fond des cours d'eau. Il est ainsi curieux de constater que l'absence de pollution nitratée de la rivière puisse contribuer à la mobilisation du manganèse. 


\subsection{Caractéristiques microbiologiques}

Les plus fortes valeurs de biomasse et de production bactériennes s'observent dans" le Lot. Les teneurs sont plus faibles dans l'eau de nappe et surtout dans l'eau des forages en anaérobiose. Elles. sont toutefois certainement sous-ëstimées dans de grandes proportions : en effet, les bactéries de l'eau ne représentent qu'une faible partie des bactéries du milieu poreux qui sont essentiellement fixées sur les particules (Harvey et al. 1984). Une étude fonctionnelle ne peut être réalisée valablement que par une expérimentation in situ, sur des volumes d'aquifère.

\section{Conclusion}

Les conditions nécessaires à la mise en solution du manganèse sont bien connues. Il faut que les premiers accepteurs d'électrons (oxygène púis nitrate) aient disparu afin que le manganèse $\left(\mathrm{Mn}^{4}+\right)$ solide soit réduit en $\mathrm{Mn}^{2+}$ soluble. Dans les eaux naturelles, où les $\mathrm{pH}$ sont proches de la neutralité et les potentiels redox inférieurs à $450 \mathrm{mV}$, l'ion manganeux ainsi mobilisé ne peut être précipité que par les sidéro-bactéries (Leptothrix, Crenothrix, etc...) mises en évidence dans les bâches et sur les crépines des forages et utilisées pour le traitement biologique.

Dans le champ captant de Capdenac-Gare, deux processus de solubilisation ónt été mis en évidence :

- le premier, qualifié d'effet de vase, met en cause la matière organique particulaire enfouie dans les vases sédimentaires ou à lá surface des sédiments actuels, dans les zones de calme ou de retour. L'eau pompée à travers ce type de milieu peu poreux est désoxygénée toute l'année, dénitrifiée et enfin chargée en $\mathrm{Mn}^{2+}$, et éventuellement $\mathrm{Fe}^{2+}$. Le manganèse reste en solution le long du trajet Lot-forages et se retrouve au niveau de FE2 et $F E 6$, avec une atténuation chez ce dernier due à la réoxygénation. Le fer précipite au cours de ce même parcours ;

- le deuxième processus, qualifié d'effet de berge, fait intervenir de la matière organique apportée par l'eau du Lot sous forme soluble. La berge se comporte comme un réacteur à bactéries fixées. La mobilisation du manganèse présent dans les alluvions dépendra du rapport entre le COD dégradable (variable) et la concentration en oxygène de l'eau du Lot qui, du fait de la diffusion et de l'activité photosynthétiqưe, demeure élevée quelle que soit la température. Celle-ci, en revanche, régule l'activité biologique au niveau de la berge et permet l'existence de conditions anaérobies dans les biofilms pour des valeurs supérieures à $14^{\circ} \mathrm{C}$ environ.

Lorsque le carbone biodégradable est épuisé, on observe une réoxygénation de l'eau par la surface, par simple diffusion ou par l'eau de pluies. Ceci permet aux bactéries de précipiter le manganèse, qui disparaît. C'est le processus, observé le long du trajet Lot, FE4, FE3, FE5.

L'effet de vase qui ne peut être supprimé et mène au traitement spécifique de l'eau exploitée doit donc faire l'objet de mesures préventives. Il peut être évité par l'implantation des captages dans des zones où le potentiel rédox est suffisamment élevé ; il faut donc généralement éviter les zones correspondant à des rives convexes où les dépôts de barre de méandre peuvent contenir de la matière organique.

Les rives rectilignes ou concaves ne mettent pas à l'abri de l'effet de berge mais ce dernier peut être contourné lorsqu'intervient une réoxygénation de la nappe par la surface, soit naturellement, soit artificiellement. L'oxygénation naturelle dépend de la granulométrie des limons d'inondation (ici sableux). D'autre part, il est évident qu'une couverture forestière, source de matière organique, a un rôle positif tant qu'il s'agit de dénitrification mais devient nocive lorsque ce stade est dépassé ; on observe alors la mobilisation du manganèse, du fer et éventuellement la présence d'ammoniaque et d'hydrogène sulfuré (Labroue \& Pinay 1986).

\section{Travaux cités}

Bernard C. \& Serieys J.M. 1986. - Déferrisation. Démanganisation biologique des eaux souterraines in situ. L'eau, $l$ 'Industrie, les Nuisances, 99 : 44-46.

Bourg A., Darmendrail D. \& Ricour J. 1989. - Geochemical filtration of Riverbank and migration of heavy metals between the Deule River and the Ansereuilles Alluvion-Chalk aquifer. Geoderma, $44: 229-244$.

Braester C. \& Martinell R. 1988. - The Vyredox and Nitredox methods of in situ treatment of groundwater. Wat. Sci. Tech., 20 (3) : 149-163.

Chauve P., Mania J., Mignot C., Recoules A., Remy F. \& Truche C. 1986. - Paramètres physico-chimiques, lithologiques et hydrologiques influençant l'évolution dans le temps des teneurs en fer et manganèse ; critique des résultats obtenus sur des champs expérimentaux de la plaine alluviale de la Saône (Franche-Comté). Journal of Hydrology., 86 : 367-390.

Clark F.M., Scott R.M. \& Bone E. 1967. - Heterotrophic ironprecipitating bacteria J.A.W.W.A. : 1037-1042.

Di-Ruggiero J. \& Gounot A.M. 1990. - Microbial manganese reduction mediated by bacteriąl strains isolated from aquifer sediments. Microb. Ecol., $20: 53-63$. 
Furman J.A. \& Azam F. 1982. - Thymidine incorporation as a measure of heterotrophic bacterioplankton production in marine surface waters : evaluation and fields results. Mar. Biol., 66 : 109-120.

Ghiorse W.C. 1988. - Microbial reduction of manganese and iron. In Biology of Anaerobic Microorganisms Zehnder A.J.B. ed., John Wileys \& Sons, New-York : 305-381.

Gounot A.M. \& Haroux C. 1986. - Manganese transformations in aquiferous sediments. In Microbial communities in soil, Jensen J.V., Kjoller A. \& Sorensen L.M. eds. Elsevier : 293-304.

Gounot A.M., Di Ruggiero J. \& Haroux C. 1988. - Bacterial manganese transformations in groundwaters. In Current perspectives in environmental biogeochemisty. GiovannozziSermanni G. \& Nannipieri P. eds. : 371-382.

Gounot A.M., Di-Ruggiero J. 1991. - Rôle géochimique des bactéries dans les eaux souterraines : exemple du cycle du manganèse dans les nappes aquifères. Hydrogéologie, 3 : 249-256.

Harvey R.W., Smith R.L. \& George L. 1984. - Effect of organic contamination upon microbial distributions and heterotrophic uptake in a Cape-cod, Mass., aquifer. Appl. Environ. Microbiol., 48 : 1197-1202.

Jacobs L.A., Von Gutten H.R., Keil R. \& Kuslys M. 1988. Geochemical changes along a river-groundwater infiltration flow path : Glattfelden, Switzerland. Geochim. Cosmochim. Acta., 52 : 2693-2706.

Labroue L. \& Pinay G. 1986. - Epuration naturelle des nitrates des eaux souterraines. Possibilités d'application au réaménagement des lacs de gravières. Annis. Limnol., 22 (1) : 83-88.
Lovley D. 1991. - Dissimilatory Fe (III) and Mn (IV) reduction. Microbiological Reviews : 259-287.

Mallessard G. 1983. - Sur la présence de fer et de manganèse dans l'aquifère alluvial de la plaine d'Avignon (Vaucluse). Relations avec l'hydrochimie et l'hydrogéologie. Thèse 3ème cycle Avignon : $121 \mathrm{p}$.

Mouchet P., Magnin J., Mazounie P., Puill A. \& Fressonet B. 1985. - Elimination du fer et du manganèse contenus dans les eaux souterraines : problèmes classiques, progrès récents. Wat. Supply, $3: 137-149$.

Mulder E.G. 1972. - Le cycle biologique tellurique et aquatique du fer et du manganèse. Rev. Ecol. Biol. Sol, 9 (3) : 321-348.

Nealson K.H., Tebo B.M. \& Rosson R.A. 1988. - Occurence and mechanisms of microbial oxidation of manganese, $A d v$. Appl. Microbiol., 33 : 279-318.

Servais P. \& Lavandier P. 1993. - Cohérence des productions bactériennes estimées à partir de l'incorporation de $3 \mathrm{H}$ - thymidine et de $3 \mathrm{H}$ - leucine dans les eaux douces naturelles. C.R. Acad. $\dot{S} c i$. Paris, Sciences de la vie/Life sciences, 316 : 642-646.

Simon M. \& Azam F. 1989. - Protein content and protein synthesis rates of planktonic marine bacteria. Mar. Ecol. Prog. Ser., 51 : 201-213.

Sposito G. 1989. - The chemistry of soils. Oxford University Press : 277 p.

Stone A.T. \& Morgan J.J. 1984. - Reduction and dissolution of manganese (III) and manganese (IV) oxides by organics : 2 Survey of the reactivity of organics. Environ. Sci. Technol., $18: 617-624$.

Stum W. \& Morgan J.J. 1981. - Aquatic chemistry. John Wileys \& Sons, New-York : 780 p. 